thesising the colours of the spectrum by reflection from seven moveable mirrors. With the mirrors placed at equal distances from each other, the spot of compound light is not white but yellow, that is to say, it is yellowish white, the colours lost between the mirrors being just those necessary to bring out the full white.

\section{J. WOODWARD}

\section{Meteor}

A FINE meteor was seen here to-night at about 9. ro P.M. ; it was described to me as starting from near $\theta$ Orionis, and proceeding towards a point a little north of $\gamma$ Eridani, when it was lost behind a belt of cloud.

Rugby, Feb. ${ }_{3}$

J. M. WILSON

\section{Snake Bites}

IN NATURE of Dec. 22 I notice a note extracted from the Pall Mall Gazette, giving a return of the excessive number of deaths which take place anmually in the Bengal Presidency, from the effects of snake-bite. That $x I, 416$ persons die from this cause alone," "and that no efficacious means are adopted to check its ravages," are very startling announcements, and strike me as being well worth the attention of the readers of NATURE.

Upwards of a year ago Dr. Fayrer recorded an elaborate series of experiments on snake poison, in the Indian Medical Gazette, from which he concludes "that if an animal, and probably a $\mathrm{man}$, be fairly bitten by a fresh and vigorous cobra or daboia, it or he will inevitably succumb unless some immediate or direct method of arresting the entering of the poison into the circulation be practised." This direct method is to apply ligatures and cauterisation; for, says the same authority, "to conceive of an antidote, in the true sense of the term, to snake poison, one must imagine a substance so subtle as to follow, overtake, and neutralise the venom in the blood, or that shall have the power of counteracting and neutralising the deadly infuence it has exerted on the vital forces." I remember reading some time ago of another doctor in India or Australia, who had tried ammonia as an antidote, but I cannot recollect with what result. It seems to me, however, that this real antidote has still to be found: and cauterisation, to prove effectual, must follow the course of the poison, which it cannot do; nor, indeed, is it possible for it to do much more than burn the walls of the wound, so it is not to be wondered at if some of those subjected to this powerful treatment do not recover.

I have long thought that the best cure for snake-bite would be powerful suction, applied to the wound by means of an instrument made for the purpose, and similar in principle to a boy's sucker. This would draw off a considerable quantity of the blood in the neighbourhood of the wound, and by so doing wash the poison out before it. Above the wound there might be a ligature applied, but sufficiently distant from it to ensure that the blood in the small vessels between the wound and ligature be competent to wash out the poison.

Where such an instrument is not at hand, and the assistance of a second party can be obtained, he might tie a ligature above the wound, and suck the latter with his mouth for a considerable time, spitting out all the saliva and blood which accumulates. It would be advisable, too, to make the wound a little larger before commencing to suck, with a sharp knife or otherwise, in order that the greater flow of blood may the better discharge the poison. The operation of sucking the poison into the mouth need not be feared, for even although a sinall portion of it were swallowed, it could do no harm. I believe I am correct in stating that a quantity of poison which will prove fatal on entering the circulation, would have no injurious effect when taken into the stomach. Where the bite is in such a part of the body that the party bitten can easily suck it himself, then he ought to do so: but unfortunately this is seldom the case, it usually being the lower extremities which are attacked.

In support of this method, I may say that I read, two or three years ago, an account of how the bites of snakes were counteryeted in a woody portion of South America. The writer said when any one was bitten-and there were one or two almost daily-he was sure to die in thirty minutes to one hour afterwards if his wound was not immediately sucked. There, however, in order to make quite certain that the poison, when sucked out of the wound, would have no injurious effect on the sucker, the latter filled his mouth with olive oil betore applying it to the wound : and I imagine this would be a sure precaution, for it provides a plentiful supply of matter for the poison to diffuse in, without interfering much with the absorbents of the mouth. The result of this writer's experience was that the bitten person seldom, if ever, died; and he who sucked the wound never felt an injurious effect.

This subject seems so important that I have ventured to address you at this length upon it, in the hope of drawing from some of your correspondents further details concerning antidotes and methods of curing snake-bite.

T. L. PATTerson

\section{The Cretaceous Period}

In NATuRE of Jan. 19, a letter appeared from Prof. Wyville Thomson defending the expressions, "we are still living in the Cretaceous epoch," "the chalk is being formed at present in the bed of the Atlantic." When first this announcement was made, it was followed up by various strong comments implying that the similarity of the Atlantic mud to the chalk in lithological character, and in many of the imbedded organisms * "would seem to unsettle much that has generally been accredited to geological science," would, in fact, revolutionise geological classification.

As these unfortunate expressions are again put forward, notwithstanding the protest of our most distinguished geologists, $\dagger$ Sir Roderick Murchison and Sir Charles Lyell, + it may be useful to consider what the question at issue really is. Simply stated, it is this: Have we sufficient evidence for drawing one of our strongest lines at the base of the tertiary deposits, and saying that it marks the commencement of a new epoch or period? $\$$

In grouping the rocks, we have been obliged frequently to adopt an arbitrary classification. The thickness will not furnish the necessary tests, as accumulation is more rapid at one time and place than another. Lithological character will not do alone, as a bed often passes both vertically and horizontally into one quite different. The organic remains will not do alone, as the fauna migrated and re-migrated to suitable areas when favour. able conditions recurred.

But sometimes we have the commencement of a new period well defined by seeing that the group of deposits which form the record of it rest unconformably on an older formation, which has been in part at least heaved up, denuded, and used to form the new series. At the bottom of this newer series we must infer a considerable break-a portion of unrepresented time.\| This time may be represented elsewhere, but we have a point in time well marked by the first grain of the new deposit laid upon the older denuded rocks.

So we are quite safe in saying that there had been a considerable lapse of time, and that new conditions prevailed over large areas when the Cambrian was laid unconformably upon the Laurentian, when the Upper Old Red was laid unconformably on the Lower Old Red and Silurian, when the Permian was laid unconformably on the Carboniferous and more ancient rocks.

Probably deposition went on longer over one area than another-very likely deposition has never in the earth's true geological history been entirely arrested, so that the connecting deposits between any two formations and intermediate forms of life may possibly still be preserved under the depths of ocean or on the vast still unexplored continents. It would be of course difficult under such circumstances to identify in a series of more or less continuous deposits the base line we have so well marked elsewhere by visible unconformity; and this difficulty occurs in the older rocks, as, for instance, in the case of the base of the Upper Old Red or Carboniferous in South Wales, of the Permian when the Rotheliegende is present, and many others, but this arises from our want of data. We might fairly hope that if we could find the continuous deposits after enormous intervals represented by known unconformities, we should read a wonderful story, and know, for instance, more clearly by what variation of forms and invasion of stronger life from adjoining areas wa are left at the end of a long period with an ammonite instead of a goniatite, or a nautilus instead of either.

Now, to return to the particular case under notice. Have we at the bottom of the Tertiary formations evidence of a break so large, of a lapse of unrepresented time so long, of a change in conditions over large areas so great that, we are justified in saying that this is a convenient place to draw one of our strong lines?

\footnotetext{
$f$ Pres. Add. Geog. Sect. B.it. Assoc., Liverpool, 1870

Students' Elements of Geology, $187 x$

See also an able article by Mr. Green, Geol. Mag., Jan. 1870 See Ramsay, Pres. Add. Geol. Soc., r863-4.
} 